Original Article

\title{
Common Histopathological spectrum of Posterior Fossa Tumors in Pediatric Age Group
}

\author{
Ayaz Ahmad, Mushtaq Khan, Sohail Amir, Muhammad Ali Numan, Atif Aman, Shahid Ayub \\ Neurosurgery department MTI Hayatabad Medical Complex Peshawar, Pakistan
}

\begin{abstract}
Objective: To know about the common posterior fossa tumors in the pediatric age group on basis of Histopathology in Neurosurgery Department, Hayatabad Medical Complex Peshawar.

Material and Methods: This descriptive cross-sectional study was conducted in the department of MTI Hayatabad medical complex Peshawar from January 2017 to January 2020. We included a total of 52 patients who operated for posterior fossa tumors and biopsy reports were observed to know the histological pattern of the tumor. We included all those patients who have posterior fossa tumors except those tumors which involved or arise from brain stem and infections. The data was collected and analyzed using SPSS version 21.
\end{abstract}

Results: Our study shows that the mean age was 6 years with a standard deviation \pm 2.81 . Fifty-eight percent of children were male and $42 \%$ of children were female. Histopathologic patterns were analyzed as $48 \%$ of children had Medulloblastoma, 25\% of children had Astrocytoma, 19\% of children had Ependymoma, $8 \%$ of patients had other histopathologic patterns.

Conclusion: Our study concludes that common histopathologic patterns of posterior fossa tumors in children were medulloblastoma (48\%), Astrocytoma (25\%), ependymoma (19\%) respectively.

Keywords: Histopathologic Spectrum, Posterior Fossa Tumors.

Corresponding Author: Ayaz Ahmad

Department of Neurosurgery

MTI, Hayatabad Medical Complex

Peshawar - Pakistan

Email: ayaz.neurosurgeon@gmail.com

Date of Submission: 20-10-2021

Date of Revision: 19-11-2021

Date of Acceptance: 28-11-2021

Date of Online Publishing: 31-12-2021

Date of Print: 31-12-2021

DOI: $10.36552 /$ pjns.v25i4.613

\section{INTRODUCTION}

Infratentorial tumors comprise between $54-70 \%$ of pediatric brain tumors compared to $15-20 \%$ in the adult population. The commonest pediatric posterior fossa tumors are medulloblastoma (20\%) brainstem glioma (15\%), astrocytoma (15\%), and eight percent ependymomas. ${ }^{1,3}$

Tumors of the central nervous system are the second commonest pediatric tumors (20\%) after leukemia (37\%) and the most common solid pediatric tumors comprise $40-50 \% .^{1,2}$

The incidence of brain tumors in children is 
2 - 3.5 per 1 Lac population. The mean age at diagnosis has decreased from nine years in 1970 to the current figure of 6.5 years in $2000 .^{4}$

The clinical findings in a child with infratentorial mass have been determined by the tumor location and histologicaltype. A child with posterior fossa mass may present with headache, gastrointestinal symptoms like nausea/vomiting, a decrease of vision, cranial nerve deficit, motor or sensory deficit. Most of the clinical signs are related to mass effect of the neural structures in the posterior fossa, such as the cerebellum, brainstem or the effects of vascular compromise or increased intracranial pressure (ICP) and hydrocephalus. ${ }^{4,5}$

Anatomical variability in the posterior fossa, the complicated structural framework of the contents, and the need for microsurgical dissection in tumor surgery has made the surgery of posterior fossa tumors one of the most difficult entities among the surgical approaches in neurosurgery. ${ }^{6,7}$

Diagnosis of the posterior fossa is usually delayed in children due to non-specific signs and symptoms, constraints of the financial status of families, and geographic location which influences the availability of neurosurgical diagnostic or treatment services or the distance from it. Initial radiologic investigations usually include CT brain which may give gross clues about the status of the intracranial contents or associated hydrocephalus in such cases. Similarly, the more sensitive diagnostic study is the MRI brain and vascular investigative studies. The gross nature of the tumor in the posterior fossa can be concluded from its radiologic appearance, especially on MRI. ${ }^{8,9}$ Management depends primarily upon the time of presentation of the child. If the patient has developed gross hydrocephalus, it is diverted via shunt systems. If the CSF circulatory pathways are still open, then first the tumor is resected and the development of hydrocephalus is watched for in follow-up visits. Chemo-radiotherapy, stereotactic radiosurgery, and palliative decompression of the tumors are also viable options depending upon the individual case and indications. ${ }^{10}$

Survival has improved for posterior fossa children from $20 \%$ in 5 years to up to $70 \%$ in cases of medulloblastoma, while others are completely cured such as astrocytoma, meningioma, or dermoids. ${ }^{11}$ Determination of the histopathologic patterns of pediatric posterior fossa tumors and their demographics are essential for better understanding the natural history of this disease entity. The sources of the available data about the incidence of pediatric posterior fossa tumors have largely been from western populations which do not match the true nature of the demographics in our population.

The posterior cranial fossa is a space below the tentorium cerebelli, guarded anteriorly by the clivus and sphenoid bone and anterolaterally by the petrous temporal bones, posteriorly and posterolateral by the occipital bone and a smaller part of the parietal bone.

This study will focus primarily upon the distribution and frequency of histopathologic subtypes of posterior fossa tumors. This understanding will help us or better classification of the distribution of this disease entity in our population and help us in designing proper management protocols.

\section{MATERIAL AND METHODS}

This cross-sectional descriptive type study was conducted in the Neurosurgical Department MTI Hayatabad Medical complex Peshawar from Jan 2017 to Jan 2020.

\section{Inclusion Criteria}

In this study, we included a total of 52 patients who were diagnosed case of posterior fossa tumor (cerebellar or fourth ventricle) on imaging studies as shown in Figure 1. Biopsy report collected after posterior fossa tumors surgery and was analyzed for histopathological pattern. 


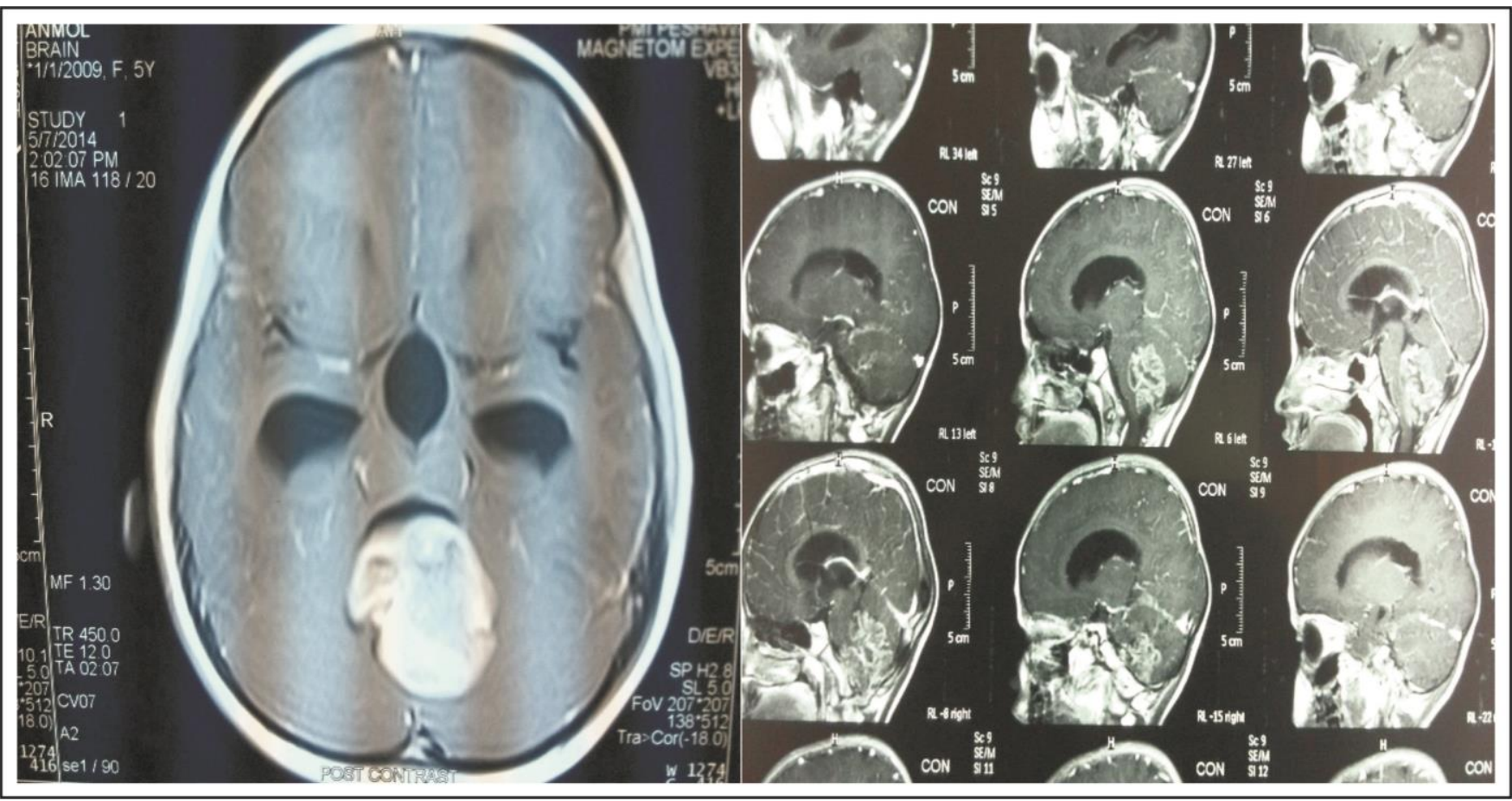

Figure 1(a): MRI brain axial image.

Figure 1(b): MRI brain sagittal image.

Figure 1: MRI Brain Lesions in Posterior Fossa. Scans used with patient's permission.

\section{Medulloblastoma}

Microscopically polygonal cells around blood vessels and necrosis.

\section{Ependymoma}

Microscopically oval to spindle shape cells was present arranged in sheets.

\section{Astrocytoma}

Microscopically bipolar astrocytes cells were present. As shown in Figure 2.

\section{Excluded Criteria}

We excluded those patients who had infections or brain stem tumors.

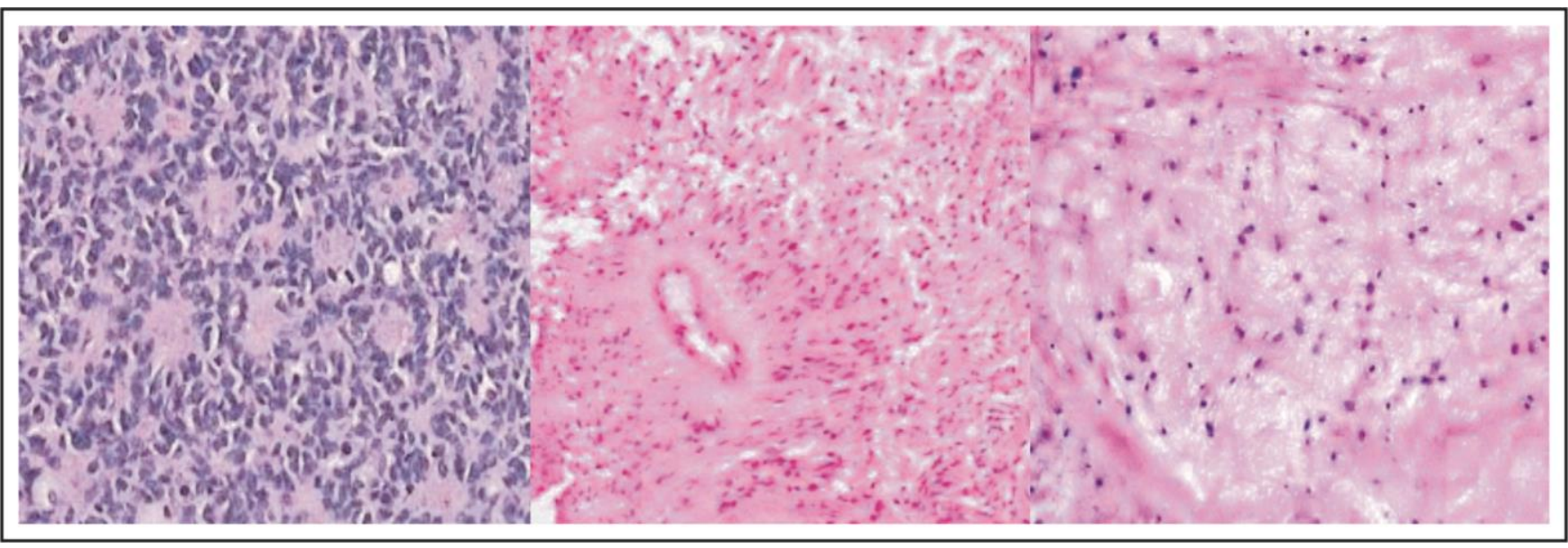

Figure 2(a): Medulloblastoma.

Figure 2(b): Ependymoma.

Figure 2(c): Pilocytic Astrocytoma.

Figure 2: Histology of common posterior fossa tumors. Images used with patient's permission 


\section{Data Collection}

This study was approved by Institutional Research $\&$ ethical Board and informed consent were taken from patients or relative. We collected the relative data in a pre-designed proforma. Then the data were analyzed by using SPSS version 25 .

\section{RESULTS}

This study was conducted in the Department of Neurosurgery MTI Hayatabad Medical Complex Peshawar in which we included a total of 52 patients who were operated upon for posterior fossa tumors. The biopsy reports were obtained to know about the common histopathology of posterior fossa tumors in the pediatric age group in our community.

\section{Age Distribution}

After analyzing the results, the most frequent posterior fossa tumors were observed in age group 1 - 5 years. Which was 24 (46\%), 18 (34\%) children were in the age group $6-10$ years while $10(20 \%)$ children were in the age group $11-16$ years. The mean age was 6 years with a standard deviation \pm 2.81 (Table 1 ).

\begin{tabular}{|c|c|c|}
\hline Age & Frequency & Percentage \\
\hline $1-5$ years & 24 & $46 \%$ \\
\hline $6-10$ years & 18 & $34 \%$ \\
\hline $11-16$ years & 10 & $20 \%$ \\
\hline Total & 52 & $100 \%$ \\
\hline
\end{tabular}

Mean age was 6 years with a standard deviation \pm 2.8

\section{Gender Distribution}

Gender distribution among 52 children was analyzed as 30 (58\%) children were male and 22 (42\%) children were female (Table 2).

\begin{tabular}{|lcc|}
\hline Table 2: & Gender Distribution $(\mathrm{n}=52)$ \\
Gender & Frequency & Percentage \\
Male & 30 & $58 \%$ \\
Female & 22 & $42 \%$ \\
Total & $\mathbf{5 2}$ & $\mathbf{1 0 0} \%$ \\
\hline
\end{tabular}

\section{Histopathological Spectrum}

Histopathologic spectrum among 52 children was analyzed as 25 (48\%) children had Medulloblastoma, 13 (25\%) children had Astrocytoma, 10 (19\%) children had Ependymoma, 4 (8\%) children had another Histopathologic spectrum (As shown in Table 3).

\begin{tabular}{|l|cc|}
\hline \multicolumn{3}{l}{ Table 3: Histopathologic Spectrum $(\mathrm{n}=52)}$. \\
$\begin{array}{l}\text { Histopathologic } \\
\text { Spectrum }\end{array}$ & Frequency & Percentage \\
Medulloblastoma & 25 & $48 \%$ \\
Astrocytoma & 18 & $25 \%$ \\
Ependymoma & 10 & $19 \%$ \\
Other & 4 & $8 \%$ \\
Total & $\mathbf{5 2}$ & $\mathbf{1 0 0} \%$ \\
\hline
\end{tabular}

\section{DISCUSSION}

Most children having posterior fossa tumors are very ill on presentation, with severe headache and vomiting as a result of non-communicating hydrocephalus. Some of these patients having brainstem compression often present, rapid and sudden deterioration is always a danger. ${ }^{12}$ There are different treatment options for posterior fossa tumors which include surgery, radiotherapy, and chemotherapy. The surgical objectivity to complete surgical resection for nearly all tumors. Further, the different types of tumors were tried to identify and this was also strived to determine the different Histopathological conditions that may occur in precedence to posterior fossa and also tried to determine their level of incidence or frequency. ${ }^{13}$

Our study shows that $46 \%$ ofchildren were in the age group 1 to 5 years, $34 \%$ of children were in 
the age range $6-10$ years, twenty percent of children were in the age range $11-14$ years. The mean age was 6 years with a standard deviation \pm 2.81. Fifty-eight percent of children were male and $42 \%$ of children were female. Histopathologic patterns were analyzed as $25 \%$ of children had Medulloblastoma, $20 \%$ of children had Astrocytoma, 15\% of children had Ependymoma, $40 \%$ of patients had other histopathologic patterns.

Another study was conducted by Shaikh HA et $\mathrm{al}^{14}$ in which $A$ total of 66 patients were included. The mean age of the patients was 8 years with \pm 8.49 quite similar to our study. The minimum age of the patient was 4 months and a maximum of 15 years. There were 41 (62\%) males and 25 (38\%) females. Medulloblastoma was the commonest tumor found in $27.3 \%$ of cases followed by Astrocytoma found in $22 \%$ of cases and Ependymoma (18.2\%).

Sajid $\mathrm{H}$ et al also conducted a study about posterior fossa tumors in which Astrocytoma comprised $39 \%$ of all intracranial tumors of childhood. Medulloblastoma (20\%) ranked the second most prevalent brain tumor followed by ependymoma (13\%), choroid plexus carcinoma and malignant meningioma constituted $1.8 \%$ each. ${ }^{15}$

Similar results were also observed in another study by Rehman $A U$ et $\mathrm{al}^{16}$ in which the distribution was 43 (69.35\%) male and 19 (30.65\%) female genders. In his study, 38 (61.29\%) were adults and 24 (38.71\%) were children. On histopathological reports, the following posterior cranial fossa tumors were identified., Schwannoma (19.3\%), Meningioma: (11.2\%) Acoustic Neuroma (32.25\%), Medulloblastoma (24.5\%), Pilocytic Astrocytoma (18\%).

It has concluded through extensive analysis that among the pathological conditions medulloblastoma is the most frequently occurring as its frequency seen was $24.88 \%$ that is 54 of the 217 patients included in the study were observed have. $^{17}$ The second most seen regarding occurrence in the patients of posterior fossa was cerebellar astrocytoma which frequency after analysis observed was $19.81 \%$ that is 43 out of 217 patients of posterior fossa were suffering from cerebellar astrocytoma as well. ${ }^{18}$ The third position regarding the subsequent pathological condition to posterior fossa was occupied by Ependymoma whose occurrence frequency was seen as $13.82 \%$ that is 30 out of 217 were having Ependymoma as after posterior fossa. ${ }^{19}$ The next level of subsequent disorder with posterior fossa was brain stem glioma which occurrence seen was the same as that of Ependymoma is $12.9 \%$ or 28 patients out of 217 of posterior fossa were also having brain stem glioma. ${ }^{20}$ Further, it was also seen that Meningioma, Dermoid/Epidermoid, Hemangioblastoma, Arachnoid cyst, and Miscellaneous pathogenic conditions occurrence in the patients of posterior fossa were $7.83 \%$, $6.91 \%, 4.61 \%, 2.76 \%$, and $6.45 \%$ which were 17 , $15,10,6$, and 14 out of 217 patients. ${ }^{21}$

\section{CONCLUSION}

Our study concludes that the common histopathologic spectrum of posterior fossa tumors in children was medulloblastoma (48\%), Astrocytoma (25\%), ependymoma (19\%).

\section{REFERENCES}

1. Rehman AU, Lodhi S, Murad S. Morphological pattern of posterior cranial fossa tumors. Ann King Edward Med Uni. 2009; 15 (2): 57-9.

2. Khan AA, Ali M, Ayub S, Khanzada K, Hussain R. Histological findings of posterior fossa tumors in children. J Postgrad Med Inst. 2010; 24 (1): 31-35.

3. Faheem KM, Jyothi V, Syama B. Pediatric tumors of central nervous system (CNS) - An epidemiopathologic research study. Int J Med Health Sci. 2012; 1(3): 73-82.

4. Nasir S, Jamila B, Khaleeq S. A retrospective study of primary brain tumors in children under 14 years of age at PIMS, Islamabad. Asian Pac J Cancer Prev. 2010; 11 (5): 1225-7. 
5. Asirvatham JR, Deepti AN, Chyne R, Prasad M.S.N, Rajshekhar V, Chacko G. Pediatric tumors of the central nervous system: a retrospective study of 1,043 cases from a tertiary care center in South India. Childs Nerv Syst. 2011; 27 (8): 1257-63.

6. Karkouri $M$, Zafad S, Khattab M, Benjaafar N, ElKacemi $H$, Sefiani $S$, et al. Epidemiologic profile of pediatric brain tumors in Morocco. Childs Nerv Syst. 2010; 26 (8): 1021-7.

7. Saavedra FM, Pastrana EA, Jiménez LM, Fernandez $\mathrm{M}$, Billoch J, Sosa I, et al. Pediatric brain tumors in Puerto Rico. P R Health Sci J. 2011; 30 (4): 195-7.

8. Makino K1, Nakamura $H$, Yano $S$, Kuratsu J, Kumamoto. Population-based epidemiological study of primary intracranial tumors in childhood. Childs Nerv Syst. 2010; 26 (8): 1029-34.

9. Alexiou GA, Moschovi M, Stefanaki K, G Sfakianos, $\mathrm{N}$ Prodromou. Epidemiology of pediatric brain tumors in Greece (1991-2008). Experience from the Agia Sofia Children's Hospital. Cent Eur Neurosurg. 2011; 72 (1): 1-4.

10. Jain A, Sharma MC, Suri V, Kale SS, Mahapatra AK, Tatke $M$, et al. Spectrum of pediatric brain tumors in India: a multi-institutional study. Neurol India, 2011; 59 (2): 208-11.

11. Nayil K, Makhdoomi R, Ramzan A, Zahoor S, Rasool M, Wani A, et al. Childhood tumors of the brain: demographic pattern over a ten-year period in the Kashmir Valley. Pediatr Neurosurg. 2011; 47 (1): 31-7.

12. O'Brien DF, Javadpour $M$, Collins DR, Spennato $P$, Mallucci CL. Endoscopic third ventriculostomy: An outcome analysis of primary cases and procedures performed after ventriculoperitoneal shunt malfunction, 2005; 103 (5): 393-400.

13. Teo $C$, Jones R. Complications of endoscopic third ventriculostomy in previously shunted patients. Neurosurgery, 2008; (1) 63: 170-7.

14. Shaikh HA, Bokhari I, Rehman L, Babar AK, Siddiqui $\mathrm{SH}$, Hashi AS. Surgical Outcome of Posterior Fossa Brain Tumors. J Surg Intern. 2014; 9 (1): 26-30.

15. Sajid H. Shah, Irshad N. Soomro, Akbar S. Hussainy, Sheema H. Hassan. Clinico-morphological Pattern of Intracranial Tumors in Children. PMA. 2013; 2: 16.

16. Rehman AU, Lodhi S, Murad S. Morphological Pattern of Posterior Cranial Fossa Tumors, 2009; 15 (2): $57-9$

17. Paul H. Chapman, Eric Cosman, Michael Arnold. Telemetric ICP monitoring after surgery for posterior fossa and third ventricular tumors. Journal of Neurosurgery, 1984; 60 (3): 649651.

18. Drake JM, Kestle JR, Milner R, Cinalli G, Boop F, Piatt J Jr, et al. Randomized trial of cerebrospinal fluid shunt valve design in pediatric hydrocephalus. Neurosurgery, 1998; 43: 294-3.

19. J Hyam, J Turner, D Peterson. Cerebellar haemorrhage after repeated burr hole evacuation for chronic subdural haematoma. Journal of Clinical Neuroscience, 2007; 14 (1): 83-6.

20. Hader WJ, Walker RL, Myles ST, Hamilton M. Complications of endoscopic third ventriculostomy in previously shunted patients, 2008; 63 (1) 74 : 174-5.

21. Jenkinson $M D$, Hayhurst $C$, Al-Jumaily $M$, Kandasamy J, Clark S, Mallucci CL. The role of endoscopic third ventriculostomy in adult patients with hydrocephalus. J Neurosurg. 2009; 110: 861-6.

\section{Additional Information}

Disclosures: Authors report no conflict of interest.

Ethical Review Board Approval: The study was conformed to the ethical review board requirements.

Human Subjects: Consent was obtained by all patients/participants in this study.

\section{Conflicts of Interest:}

In compliance with the ICMJE uniform disclosure form, all authors declare the following:

Financial Relationships: All authors have declared that they have no financial relationships at present or within the previous three years with any organizations that might have an interest in the submitted work.

Other Relationships: All authors have declared that there are no other relationships or activities that could appear to have influenced the submitted work. 


\section{AUTHORS CONTRIBUTIONS}

\begin{tabular}{|l|l|l|}
\hline Sr.\# & Author's Full Name & Intellectual Contribution to Paper in Terms of: \\
\hline 1. & Ayaz Ahmad & 1. $\quad$ Study design and methodology. \\
\hline 2. & Mushtaq Khan & 2. $\quad$ Paper writing and data calculations. \\
\hline 3. & Sohail Amir & 3. $\quad$ Data collection and calculations. \\
\hline 4. & Mohammad Ali Numan & 4. $\quad$ Analysis of data and interpretation of results etc. \\
\hline 5. & Atif Aman & 5. $\quad$ Literature review and referencing. \\
\hline 6. & Shahid Ayub & 6. Analysis of data and quality insurer. \\
\hline
\end{tabular}

